I N S T I T U T O

$\mathrm{DE}$

M E D I C I N A

T R O P I C A L

DE

S ÃO PAULO

JOURNAL OF THE SÃO PAULO INSTITUTE OF TROPICAL MEDICINE

(1) Universidade Estadual de Campinas, Faculdade de Ciências Médicas, Campinas, São Paulo, Brasil

(2)Western University of Health Sciences, Pomona, California, USA

Correspondence to: Paulo Eduardo Neves Ferreira Velho

Universidade Estadual de Campinas,

Faculdade de Ciências Médicas,

Rua Tessália Vieira Camargo, 126, Barão

Geraldo, CEP 13084-971, Campinas, SP,

Brazil.

Tel: + $55193521-7602$

E-mail:pvelho@unicamp.br

Received: 15 December 2016

Accepted: 6 June 2017
http://dx.doi.org/10.1590/S1678-9946201759062

\section{Chronic lymphadenopathy caused by a Brazilian strain of Bartonella henselae}

\author{
Marina Rovani Drummond', Paulo Eduardo Neves Ferreira Velho', Marcio \\ Antonio Haro Adad ${ }^{1}$, Maria Letícia Cintra', Stanley Sowy², Pedro Paulo \\ Vissotto de Paiva Diniz ${ }^{2}$
}

\section{ABSTRACT}

Bartonella henselae is a relevant causative agent of bartonelloses in humans. We described an immunocompetent patient with clinical manifestation of chronic cervical lymphadenopathy after a cat-scratch in her forearm. This case shows $B$. henselae infection persistence even after prolonged antibiotic treatment.

KEYWORDS: Bartonella. Cat-scratch disease. Lymph nodes.

\section{INTRODUCTION}

Bartonella spp. are microorganisms that can cause diseases in humans and animals ${ }^{1}$. The most involved species in human infections are Bartonella bacilliformis, Bartonella quintana and Bartonella henselae. Bartonellosis was formerly characterized as Carrión's disease that is caused by B. bacilliformis. The species $B$. quintana, the agent of trench fever, was named for its hallmark five-day fever episodes during infection. Bacillary Angiomatosis (BA), Endocarditis (E), and Cat-Scratch Disease (CSD) are other classical bartonelloses caused by a different Bartonella spp., the B. henselae which was described in 1992 and may cause BA, $\mathrm{E}$ and CSD. This species is an important agent of bartonelloses in humans and have been related to many other clinical manifestations ${ }^{2,3}$.

In Brazil, seroprevalence rates for $B$. henselae can range from 13.7 to $34.4 \%$ and $38.4 \%$ in healthy and in HIV seropositive asymptomatic individuals, respectively ${ }^{1,4-6}$. B. henselae DNA has been detected in $10.6 \%$ and $4.5 \%$ of cats in the Southern and Northeastern regions of Brazil, respectively ${ }^{6,7}$. The lack of proper control of ectoparasites, especially cat fleas, and the close interactions between pets and humans may support the transmission of these pathogens to humans in $\mathrm{Brazil}^{8}$, as has been suggested in other countries ${ }^{9}$.

\section{CASE REPORT}

A 10-year-old female girl from the countryside of Caldas, Minas Gerais State $\left(21^{\circ} 55^{\prime} 26^{\prime \prime S} 46^{\circ} 23^{\prime} 9^{\prime \prime} \mathrm{W}\right)$, Southeast region of Brazil, was presented to her pediatrician with a two-month history of a non-painful right cervical nodule of $3 \mathrm{~cm}$ in diameter. She reported a fever of $38{ }^{\circ} \mathrm{C}$ during the initial days. At the time of presentation, no fever, weight loss or other clinical signs were reported. Epidemiological data revealed that the patient had frequent contact with cats and, two months prior to presentation, she was scratched on the right forearm by a kitten from her farm. The 
patient denied taking any prescription, over-the-counter medication or illicit drugs. The patient's past medical and travel history were unremarkable. No other person in the household had similar clinical signs. Physical examination revealed an enlarged left cervical lymph node of $2 \mathrm{~cm}$ in diameter without armpit adenopathy. No other abnormalities were detected. A biopsy of her right mass revealed chronic granulomatous adenitis suggesting CSD. Tuberculosis test (PPD) and paracoccidioidomycosis serology were negative. She was properly treated for six weeks with $200 \mathrm{mg}$ /day of doxycycline with lymph node regression.

Immunofluorescence assays (IFA) detected IgG titers of 1:256 and $\operatorname{IgM}$ titers of 1:64 for $B$. henselae and $\operatorname{IgG}$ titers of $1: 256$ and IgM titers of 1:32 for Bartonella quintana (IgG cut-off 1:64 and IgM 1:16 for both species). Two years later, she had a new right cervical lymph node enlargement episode with no other concurrent symptoms. No laboratory abnormalities were detected, including protein electrophoresis and immunoglobulin analysis. Doxycycline treatment was initiated at the same previously used dose, and clinical improvement of the lymphadenopathy was obtained after a complete six-week treatment.

Approximately four years after her initial presentation, the patient was referred to and hospitalized at the University of Campinas (UNICAMP) medical teaching hospital, State of São Paulo, Brazil, due to a new mass on the left cervical region. Physical examination revealed a $4 \mathrm{~cm}$ painless, soft, freely moveable mass on the left anterior cervical region of the patient. Cervical scars (Figure 1) from previous suppuration and biopsies were also evident. No other abnormalities were found during physical examination. Cell blood count and serum chemistry were unremarkable. A computed tomographic (CT) evaluation of the neck revealed anterior and posterior cervical lymphadenomegaly, with central necrosis and calcification, while $\mathrm{CT}$ evaluation of the abdomen exhibited mesenteric lymphadenomegaly and splenomegaly, while no thoracic lymphadenopathy was observed. IFA-IgG for $B$. henselae and $B$. quintana were positive at $1: 128$. Histopathology of the lymph node and surrounding skin indicated the presence of a chronic granulomatous inflammatory process and under special stains (Giemsa and Warthin-Starry) structures suggestive of Bartonella sp were found. A fine needle aspirate of the affected cervical lymph node was also performed. Standard and Bartonella-specific lymph node pus culture presented no isolate in solid agar supplemented with 5\% sheep blood and grown in a $5 \% \mathrm{CO}_{2}$ atmosphere. An aliquot of this material was submitted for Real Time PCR to test for the presence of Bartonella DNA using sequencespecific primers: 16s-23s rRNA internal transcribed spacer (ITS) region and phage-associated protein gene (pap31) followed by DNA sequencing for bacterial identification, as previously described ${ }^{10}$. The ITS and Pap31 DNA sequences amplified from the patient were $100 \%$ identical to four and six DNA sequences of the $B$. henselae strain Brazil-1 previously described in dogs, cats and a human from Brazil, respectively (Figure 2). A definitive diagnosis of chronic lymphadenopathy due to bartonellosis was undertaken. The patient was treated with intravenous gentamicin $(160 \mathrm{mg} /$ day $)$ for two weeks and oral erythromycin ( $2 \mathrm{~g} / \mathrm{day})$ for six weeks. After having been discharged, she continued on azithromycin $(500 \mathrm{mg} /$ day) treatment for one year.

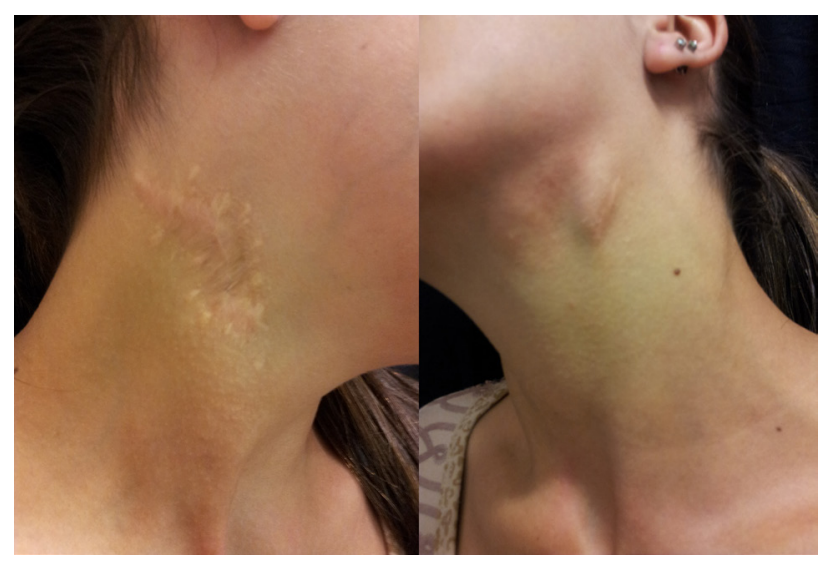

Figure 1 - Right and left cervical regions of the neck, respectively, showing site scarring from suppuration and lymphadenopathy

The patient has repeatedly sought medical attention due to spontaneous recurrent episodes of cervical lymphadenomegaly for the past two years with partial clinical resolution during new azithromycin/doxycycline treatments or even without treatments. Despite the prolonged antibiotic therapy, cervical lymphadenomegaly became persistent and has never completely regressed making the possibility of reinfections unlikely. Nowadays, she is 20 years old and is still followed up at the UNICAMP outpatient clinic because she maintains bilateral cervical lymph nodes enlargement. We have recently reported that, in the same geographic region of this case report, contact with cats is a major risk factor for Bartonella infection ${ }^{8}$. In this case report, we describe a patient with an initial clinical manifestation of chronic cervical lymphadenopathy after a cat-scratch in her forearm. Medical literature refers to patients with chronic lymphadenopathy as atypical CSD, but since the beginning of the clinical manifestation, she has had bilateral lymph nodes enlargement. Later, mesenteric lymphadenopathy was also documented, similar to previous reports as reviewed by Choi et al. ${ }^{11}$. Despite the early diagnosis of bartonellosis, the infection failed to resolve even upon prolonged and diverse antibiotic therapies, similar to a report by Simonton and Rupar ${ }^{12}$. 


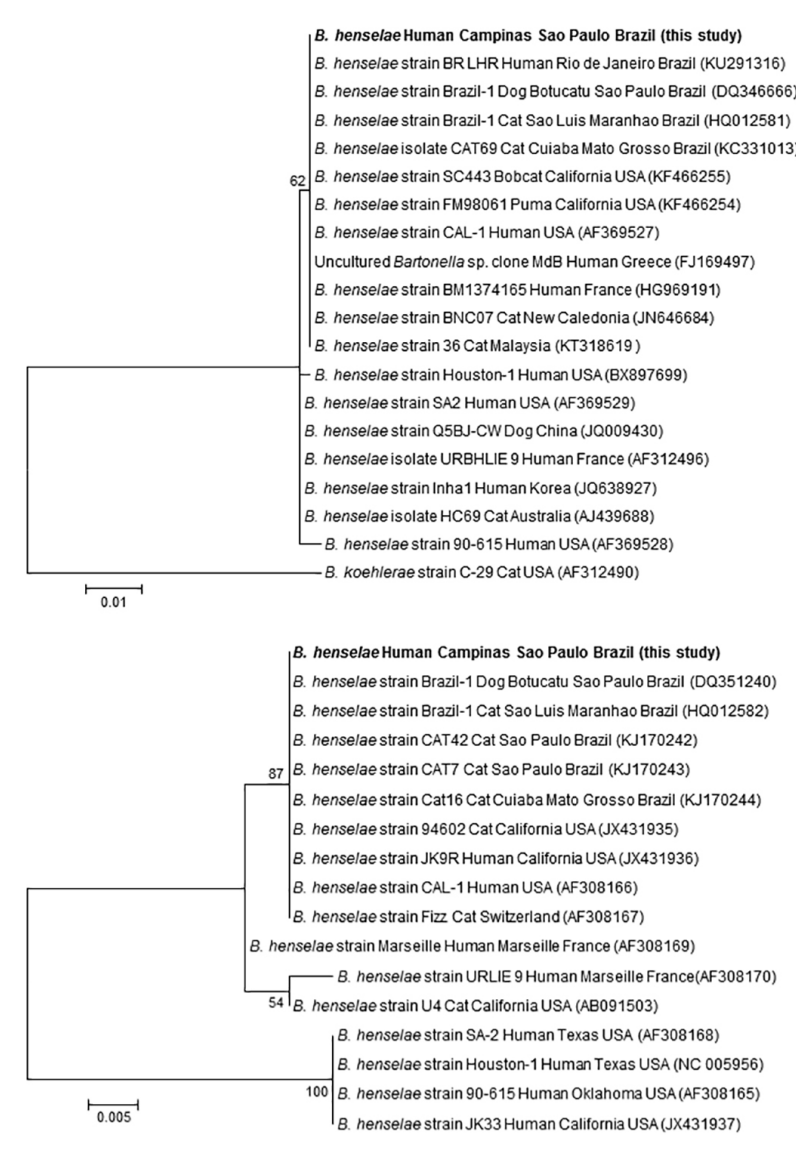

Figure 2 - Phylogenetic tree of the 16S-23S rRNA ITS region (top) and Pap31 gene (bottom) of Bartonella species closely related to the DNA sequences obtained from this patient. The phylogenetic tree was based on $579 \mathrm{bp}$ sequences of the 16S-23S rRNA Intergenic Transcribed Spacer (ITS) region and on $448 \mathrm{bp}$ sequences of the bacteriophage associated heme-binding protein Pap31 gene of selected Bartonella henselae strains and closely related species by using the Maximum Likelihood method based on the Kimura-Nei model. Each bacterial name is followed by the isolation source and geographic origin, and the GenBank accession number is provided in parentheses. The numbers at the nodes indicate percentages of bootstrap support based on 1,000 replicates. The scale bar indicates 0.01 and 0.005 substitutions per nucleotide position for the ITS region and the Pap31 gene, respectively. Phylogenetic analyses were conducted with MEGA7

We detected $B$. henselae DNA, so that IFA positive results to $B$. henselae and $B$. quintana should represent cross-reactions in the serologic diagnosis as described before $^{13}$. The phylogenetic analysis indicated that this patient was infected with a strain of $B$. henselae different from the majority of strains that have been previously identified infecting humans in the United States, Europe and Brazil (Houston-1, SA2, Marseille, 90-615, URBHLIE 9, among others) ${ }^{1,14,15}$. The DNA fragments of the ITS region and Pap31 gene of $B$. henselae obtained from this patient showed 100\% identity with the strain Brazil-1 (Figure 2), which has been described multiple times from infected cats and dogs in Brazil ${ }^{7,16}$. Furthermore, a growing number of human cases in Brazil were shown to be infected with the Brazil-1 strain, including blood donors ${ }^{1}$, suggesting that this strain may be endemic in that country. Nonetheless, the same DNA sequence of ITS and Pap31 present in this patient have also been reported in other $B$. henselae strains from cats, wild felids, and humans from the United States, Europe and Southeast Asia. Three of our B. henselae Brazil-1 isolates from cats have been deposited into the Instituto Adolfo Lutz Culture Collection and are available to the scientific community. Future genome-wide sequencing analysis will be able to further characterize the relationship of this isolate with other $B$. henselae strains reported in Brazil and in other countries around the world.

\section{CONCLUSIONS}

In summary, this report documents the detection of $B$. henselae Brazil-1 strain DNA from the lymph node of an immunocompetent patient with recurring bartonellosis episodes for several years that has persisted even after diverse antimicrobial therapies. Similar cases of recurring isolation of Bartonella sp. despite antibiotic therapy have also been reported in the veterinary literature ${ }^{12,17,18}$. In our case, the patient history did not support the occurrence of frequent re-infection episodes, although we cannot exclude this possibility. Nonetheless, this case should raise the awareness of the medical community for the persistence of Bartonella sp. infections in humans.

\section{ACKNOWLEDGEMENTS}

We thank Steven Henriksen and Dominique Griffon for providing research infrastructure and support at Western University of Health Sciences, and Hannah Mirrashed, John Greenwood and Marizete Salvadego for their technical assistance.

\section{REFERENCES}

1. Pitassi LH, de Paiva Diniz PP, Scorpio DG, Drummond MR, Lania BG, Barjas-Castro ML, et al. Bartonella spp. bacteremia in blood donors from Campinas, Brazil. PLoS Negl Trop Dis. 2015;9:e003467.

2. Florin TA, Zaoutis TE, Zaoutis LB. Beyond cat scratch disease: widening spectrum of Bartonella henselae infection. Pediatrics. 2008;121:e1413-25.

3. Angelakis E, Raoult D. Pathogenicity and treatment of Bartonella infections. Int J Antimicrob Agents. 2014;44:16-25.

4. Lamas CC, Mares-Guia MA, Rozental T, Moreira N, Favacho AR, Barreira J, et al. Bartonella spp. infection in HIV 
positive individuals, their pets and ectoparasites in Rio de Janeiro, Brazil: serological and molecular study. Acta Trop. 2010;115:137-41.

5. da Costa PS, Brigatte ME, Greco DB. Antibodies to Rickettsia rickettsii, Rickettsia typhi, Coxiella burnetii, Bartonella henselae, Bartonella quintana, and Ehrlichia chaffeensis among healthy population in Minas Gerais, Brazil. Mem Inst Oswaldo Cruz. 2005;100:853-9.

6. Staggemeier R, Venker CA, Klein DH, Petry M, Spilki FR, Cantarelli VV. Prevalence of Bartonella henselae and Bartonella clarridgeiae in cats in the south of Brazil: a molecular study. Mem Inst Oswaldo Cruz. 2010;105:873-8.

7. Braga MS, Diniz PP, André MR, Bortoli CP, Machado RZ. Molecular characterisation of Bartonella species in cats from São Luis, state of Maranhão, North-Eastern Brazil. Mem Inst Oswaldo Cruz. 2012;107:772-7.

8. Diniz PP, Velho PE, Pitassi LH, Drummond MR, Lania BG, Barjas-Castro ML, et al. Risk factors for Bartonella species infection in blood donors from Southeast Brazil. PLoS Negl Trop Dis. 2016;10:e004509.

9. Breitschwerdt EB, Kordick DL. Bartonella infection in animals: carriership, reservoir potential, pathogenicity, and zoonotic potential for human infection. Clin Microbiol Rev. 2000;13:428-38.

10. Magalhães RF, Pitassi LH, Salvadego M, de Moraes AM, BarjasCastro ML, Velho PE. Bartonella henselae survives after the storage period of red blood cell units: is it transmissible by transfusion? Transfus Med. 2008;18:287-91.
11. Choi AH, Bolaris M, Nguyen DK, Panosyan EH, Lasky JL 3rd, Duane GB. Clinicocytopathologic correlation in an atypical presentation of lymphadenopathy with review of literature. Am J Clin Pathol. 2015;143:749-54.

12. Simonton K, Rupar D. Progressive cat scratch disease despite antimicrobial therapy. J Pediatric Infect Dis Soc. 2015;4:e45-7.

13. La Scola B, Raoult D. Serological cross-reactions between Bartonella quintana, Bartonella henselae, and Coxiella burnetii. J Clin Microbiol. 1996;34:2270-4.

14. Drancourt M, Birtles R, Chaumentin G, Vandenesch F, Etienne J, Raoult D. New serotype of Bartonella henselae in endocarditis and cat-scratch disease. Lancet. 1996;347:441-3.

15. Houpikian P, Raoult D. $16 \mathrm{~S} / 23 \mathrm{~S}$ rRNA intergenic spacer regions for phylogenetic analysis, identification, and subtyping of Bartonella species. J Clin Microbiol. 2001;39:2768-78.

16. Diniz PP, Maggi RG, Schwartz DS, Cadenas MB, Bradley JM, Hegarty B, et al. Canine bartonellosis: serological and molecular prevalence in Brazil and evidence of co-infection with Bartonella henselae and Bartonella vinsonii subsp. berkhoffii. Vet Res. 2007;38:697-710.

17. Diniz PP, Wood M, Maggi RG, Sontakke S, Stepnik M, Breitschwerdt EB. Co-isolation of Bartonella henselae and Bartonella vinsonii subsp. berkhoffii from blood, joint and subcutaneous seroma fluids from two naturally infected dogs. Vet Microbiol. 2009;138:368-72.

18. Balakrishnan N, Ericson M, Maggi R, Breitschwerdt EB. Vasculitis, cerebral infarction and persistent Bartonella henselae infection in a child. Parasit Vectors. 2016;9:254. 